\title{
Comments on: "The comparison of edema and ecchymosis after piezoelectric and conventional osteotomy in rhinoplasty."
}

\author{
Can Alper Cagici ${ }^{1}$
}

Received: 5 February 2017 / Accepted: 10 February 2017 / Published online: 2 March 2017

(C) Springer-Verlag Berlin Heidelberg 2017

\section{Dear Editor,}

I read the manuscript written by Taskın et al. [1] with great interest. The authors performed a randomized study comparing two types of osteotomy in rhinoplasty: piezoelectric and conventional osteotomy. They did not find a significant difference between these osteotomies. Although the authors stated their study is "double-blinded" in the abstract section, I do not agree with them.

In this study, 90 patients were randomized into two groups: conventional and piezoelectric osteotomy. The same surgeon did all operations. A blinded examiner evaluated the postoperative ecchymosis and edema of the patients. This is the only blinding in this study. That is why this study is not double blinded as stated in the abstract section. This situation is probably overlooked and needs to be corrected.

Compliance with ethical standards

Conflict of interest The author declares that he has no conflicts of interest.

Funding This study was not funded.

\section{Reference}

1. Taşkın Ü, Batmaz T, Erdil M, Aydın S, Yücebaş K (2017) The comparison of edema and ecchymosis after piezoelectric and conventional osteotomy in rhinoplasty. Eur Arch Otorhinolaryngol 274(2):861-865

This comment refers to the article available at doi:10.1007/ s00405-016-4306-9.

Can Alper Cagici

ccagici@hotmail.com

1 ENT Department, Baskent University Adana Seyhan

Hospital, Gazipaşa Mahallesi Baraj Caddesi No. 7,

01150 Seyhan, Adana, Turkey 